\title{
QUALIDADE PÓS-COLHEITA DE BANANA, CULTIVAR D'ANGOLA, PRODUZIDA EM RIO BRANCO, ACRE
}

Ueliton Oliveira de Almeida ${ }^{1}$, Romeu de Carvalho Andrade Neto $^{2}$, David Aquino da Costa $^{3}$, James Maciel de Araújo ${ }^{3}$, Aureny Maria Pereira Lunz ${ }^{2}$

${ }^{1}$ Engenheiro Agrônomo, Dr. em Produção Vegetal pela Universidade Federal do Acre, Rio Branco, AC. E-mail: uelitonhonda5@hotmail.com

${ }^{2}$ Engenheiro Agrônomo (a), pesquisador (a) da Embrapa Acre, Rio Branco, AC.

${ }^{3}$ Engenheiro Agrônomo, Doutorando em Produção Vegetal pela Universidade

Federal do Acre, Rio Branco, AC.

Recebido em: 06/04/2019 - Aprovado em: 10/06/2019- Publicado em: 30/06/2019

DOI: 10.18677/EnciBio_2019A114

\begin{abstract}
RESUMO
A bananeira é uma importante frutífera para o Brasil, pois gera emprego e renda tanto na zona rural quanto urbana. Estudos de qualidade físico-químicas dos frutos são importantes para os produtores, já que podem ser utilizados para definir a época de colheita adequada. Objetivou-se com este trabalho avaliar as características relacionadas à qualidade pós-colheita de banana, cv. D'angola, em diferentes épocas de colheita, produzidas nas condições de Rio Branco-AC. O experimento foi conduzido no Campo Experimental da Embrapa Acre, sendo utilizado delineamento em blocos casualizados com quatro tratamentos e cinco repetições. Os tratamentos foram compostos pelas épocas de colheita de fevereiro, março, abril e maio de 2014. Avaliou-se o comprimento e o diâmetro do fruto, a acidez total titulável (ATT), o teor de sólidos solúveis totais (SST), a relação SST/ATT (Ratio) e o potencial hidrogeniônico $(\mathrm{pH})$, além da luminosidade $\left(\mathrm{L}^{*}\right)$, cromaticidade $\left(\mathrm{C}^{*}\right)$ e ângulo ${ }^{\circ}$ Hue. Os valores médios obtidos foram: comprimento do fruto $=27,35 \mathrm{~cm}$; diâmetro do fruto= 50,63 mm; ATT = 0,54; SST = 17,48 ${ }^{\circ}$ Brix; Ratio $=34,22 ; \mathrm{pH}=4,86 ; \mathrm{L}^{*}=65,83$; $C^{*}=50,27$; e ${ }^{\circ} H u e=85,27$. As épocas de colheitas não influenciaram nas características pós-colheita dos frutos de bananeiras avaliados. As bananas produzidas entre fevereiro e maio possuem qualidade pós-colheita dentro do padrão aceito para comercialização.
\end{abstract}

PALAVRAS-CHAVE: consumidor, coloração, Musa spp, parâmetros físico-químicos.

\section{POST-HARVEST QUALITY OF BANANA, CV. D'ANGOLA, PRODUCED IN RIO BRANCO, ACRE}

\begin{abstract}
The banana tree is an important fruit for Brazil, as it generates employment and income in both rural and urban areas. Physical-chemical quality studies of fruits are important for producers, since they can be used to define the appropriate harvesting season. The objective of this work was to evaluate the characteristics related to postharvest quality of banana, cv. D'angola, at different times of harvest, produced under
\end{abstract}


the conditions of Rio Branco-AC. The experiment was conducted in the Experimental Field of Embrapa Acre, using a randomized block design with four treatments and five replicates. The treatments were composed by the harvesting dates of February, March, April and May of 2014. The length and diameter of the fruit, total titratable acidity (ATT), total soluble solids (TSS), SST/ATT (Ratio) and hydrogenation potential $(\mathrm{pH})$, besides luminosity $\left(\mathrm{L}^{*}\right)$, chromaticity $\left(\mathrm{C}^{*}\right)$ and ${ }^{\circ}$ Hue angle. The average values obtained were: fruit length $=27.35 \mathrm{~cm}$; fruit diameter $=50.63 \mathrm{~mm}$; $\mathrm{ATT}=0.54 ; \mathrm{TSS}=17.48{ }^{\circ}$ Brix; Ratio $=34.22 ; \mathrm{pH}=4.86 ; \mathrm{L}^{*}=65.83 ; \mathrm{C}^{*}=50.27$; and oHue $=85.27$. The harvesting times did not influence the post-harvest characteristics of the evaluated banana fruits. Bananas produced between February and May have post-harvest quality within the accepted standard for marketing.

KEYWORDS: Musa spp, physical-chemical parameters, consumer, coloring.

\section{INTRODUÇÃO}

A bananeira (Musa spp.), originária da Ásia, pertencente à família Musaceae, é uma planta largamente cultivada em diferentes regiões do planeta e desempenha um papel importante na economia dos países produtores (ARAÚJO; NASSUR, 2017), o que contribui com a geração de emprego e renda, pois grande parte da produção é proveniente de pequenos produtores, sendo fundamental na manutenção do homem no campo.

A banana é uma das frutas mais consumidas no mundo devido ao valor nutricional e pela grande quantidade de amido, o que faz dela como integrante na alimentação básica de milhares de pessoas. Além dos valores nutricionais, como magnésio, fósforo, sódio, manganês, iodo, zinco e potássio, e vitaminas $A, B 1, B 2, B 6$, $\mathrm{C}$, niacina e ácido fólico, a fruta também possui funções nutracêuticas, denominadas de compostos bioativos que são propriedades funcionais que promovem benefícios a saúde e ao bem-estar humano (VILETE et al., 2016).

No Brasil, a banana é a segunda fruta com maior importância em termos de área plantada, quantidade produzida e valor da produção, enquanto que no estado do Acre é a primeira frutífera. Os Estados de São Paulo, Bahia, Santa Catarina e Minas Gerais são os principais produtores nacionais dessa fruta, os quais corresponderam por 50,18\% do total produzido em 2017 (IBGE, 2019). No Acre, as principais cultivares plantadas são a Prata local, Maçã e D'angola, sendo estas últimas presentes em cerca de $95 \%$ da área cultivada com banana no estado (NOGUEIRA et al., 2017).

As características físicas-químicas dos frutos são essenciais para definir técnicas adequadas de manuseio pós-colheita, bem como para a aceitação pelos consumidores. Os atributos de qualidade dos frutos, tanto físicos, como a cor e o tamanho (comprimento e diâmetro), quanto químicos, como $\mathrm{pH}$, sólidos solúveis, acidez total titulável e Ratio, podem ser avaliados para expressar a qualidade póscolheita. Estas características podem ser afetadas por diversos fatores como a região produtora, condições edafoclimáticas, cultivar, práticas culturais adotadas, espaçamentos, idade do cacho ou do fruto na colheita e épocas de ceifa (CHITARRA; CHITARRA, 2005; CASTRICINI et al., 2016; ARAÚJO; NASSUR, 2017; SANTOS et al., 2018). Como estes e outros atributos de qualidade estão relacionadas com os diversos fatores supracitados, para cada condição de plantio, manejo e cultivar, obtêm-se características físico-químicas diferenciadas nas frutas.

As bananas, normalmente são colhidas ainda verdes, porém fisiologicamente desenvolvidas e, por apresentarem respiração climatérica, o amadurecimento completa-se após a colheita. Caracterizar os frutos neste ponto de colheita permite 
fornecer informações que possam nortear ou planejar a colheita na época adequada, o transporte a mercado consumidor próximos a produção ou distantes com base na suscetibilidade a danos mecânicos, as embalagens, tamanho dos frutos, coloração, aparência e sabor, direcionando-os conforme as exigências do comércio (HANSEN et al., 2012; CASTRICINI et al., 2015).

A coloração dos frutos, medida por colorimetria, é um importante atributo de qualidade, não só por contribuir para uma boa aparência, mas também, por influenciar a escolha do consumidor no momento da compra (CASTRICINI et al., 2015; MOTA et al., 2015; VIANA et al., 2017), tendo em vista que os pigmentos envolvidos não afetam apenas a qualidade visual do fruto, mas também o seu sabor e o aroma (TAIZ; ZEIGER, 2017). Durante o amadurecimento, a maioria dos frutos sofre mudanças na cor, principalmente na casca. Desta forma, a cor se torna um atributo importante na determinação do estádio de maturação. Uma das vantagens dessa análise é a não destruição dos frutos (MOTA et al., 2015).

Portanto, como as épocas de colheitas podem influenciar nas características físicas-químicas dos frutos (CASTRICINI et al., 2016), se torna importante avaliar esses parâmetros em banana comprida, já que é a principal fruta produzida e amplamente consumida no Acre. Além do mais, a produção de plátanos ou cultivares tipo terra se apresenta como importante alternativa aos produtores, pois sua oferta não atende à demanda, o que resulta em falta da fruta na maioria das centrais de abastecimento do país (PRATA et al., 2018), sendo as informações de pós-colheita fundamentais para a comercialização, seja interna ou externa. Dessa forma, objetivou-se avaliar a qualidade pós-colheita de frutos de bananeira, cv. D'angola, em diferentes épocas de colheita nas condições edafoclimáticas do Acre.

\section{MATERIAL E MÉTODOS}

O experimento foi conduzido no campo experimental da Embrapa Acre, localizado em Rio Branco, Acre, com altitude aproximada de $160 \mathrm{~m}$. O clima da região é Am (quente e úmido), segundo a classificação de Köppen, com temperaturas máxima de $30,9^{\circ} \mathrm{C}$ e mínima de $20,8^{\circ} \mathrm{C}$, precipitação anual em torno de $1.648,9 \mathrm{~mm}$ e umidade relativa de $83 \%$ (AGRITEMPO, 2016).

O solo da área experimental é classificado como Argissolo Vermelho-Amarelo distrófico, de textura média e bem drenado. Os atributos físico-químicos do solo da área de cultivo estão expressos na Tabela 1, e os dados climáticos durante o período de condução na Figura 1. Os dados climáticos foram obtidos da estação meteorológica Rio Branco-A104, código OMM-81965, do Instituto Nacional de Meteorologia (INMET), distante a $60 \mathrm{~km}$ do local do experimento.

TABELA 1. Atributos físico-químicos da área utilizada no cultivo de bananeira terra, cv. D'angola, em Rio Branco, AC.

\begin{tabular}{ccccccccccc}
\hline $\begin{array}{c}\text { Camada } \\
\text { (cm) }\end{array}$ & $\mathrm{pH}$ & $\mathrm{Ca}$ & $\mathrm{Mg}$ & $\mathrm{K}$ & $\mathrm{Al}+\mathrm{H}$ & $\mathrm{P}$ & $\mathrm{SB}(\%)$ & Areia & Silte & Argila \\
\hline $0-20$ & & $------\mathrm{Cmol}_{\mathrm{c}} \mathrm{dm}^{-3}-------$ & $\mathrm{mg} \mathrm{L}^{-1}$ & & $----------\mathrm{g} \mathrm{k}^{-1}---------$ \\
$20-40$ & 4,60 & 1,40 & 0,79 & 0,32 & 4,43 & 9,91 & 36,18 & 315,42 & 319,88 & 364,70 \\
& 0,85 & 0,54 & 0,20 & 4,91 & 4,21 & 24,53 & 388,66 & 329,25 & 282,10 \\
\hline
\end{tabular}




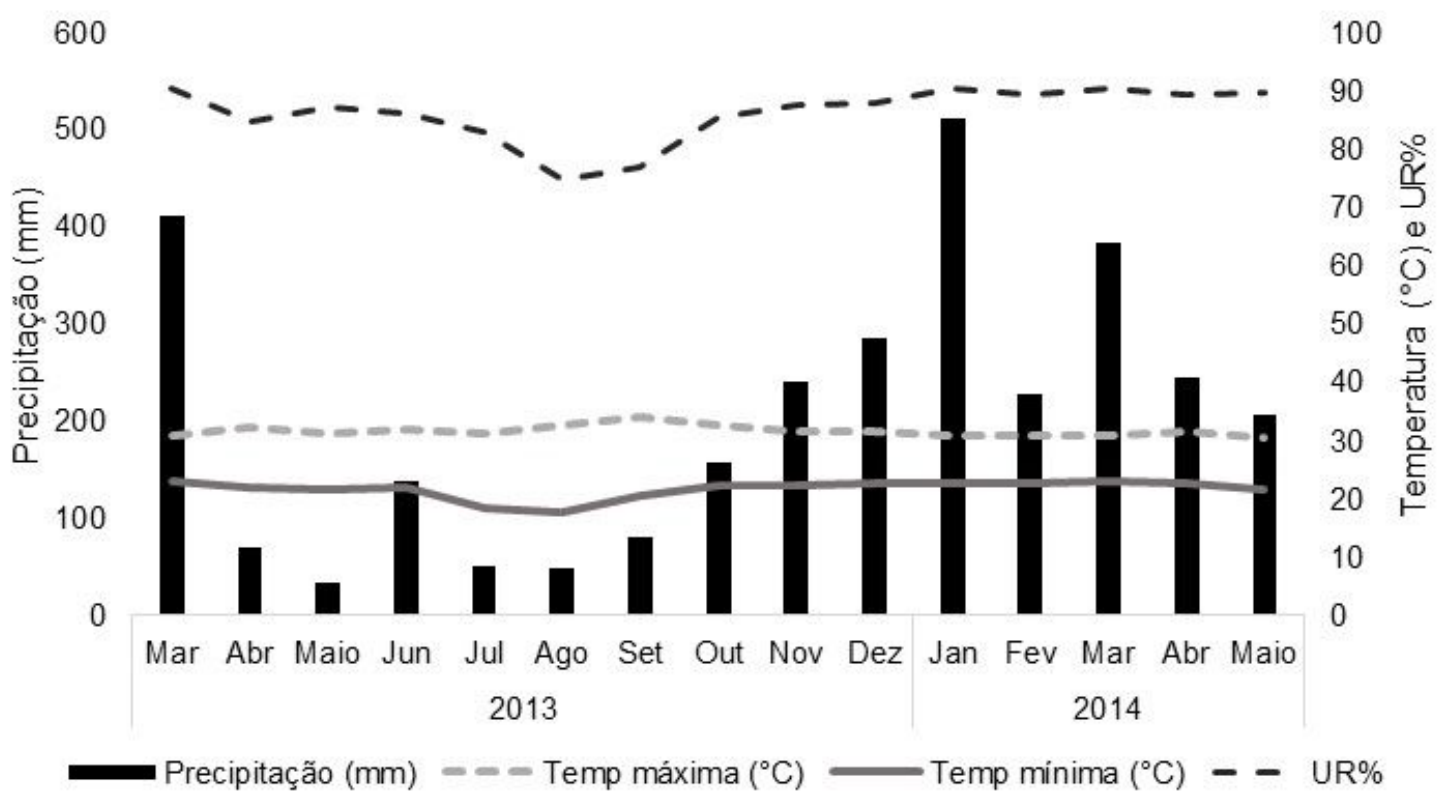

FIGURA 1. Dados meteorológicos registrados durante o cultivo de bananeira terra, cv. D'angola, entre março de 2013 e maio de 2014. Rio Branco, AC.

Fonte: INMET (2019)

As bananeiras, cv. D'angola (AAB), foram plantadas no espaçamento de $3 \times 3$ m (1.111 plantas ha $^{-1}$ ) em março de 2013, utilizando-se mudas tipo pedaço de rizoma. As covas foram abertas com broca acoplada ao trator, nas dimensões de $0,40 \mathrm{x}$ $0,40 \times 0,40 \mathrm{~m}$, e preparadas com $5 \mathrm{~kg}$ de esterco de galinha, $600 \mathrm{~g}$ de NPK 10-10-10, $800 \mathrm{~g}$ de calcário dolomítico e $50 \mathrm{~g}$ de micronutrientes (FTE BR 12), aos 30 dias antes do plantio. As adubações de cobertura foram realizadas com base na análise de solo e de acordo com a recomendação técnica da cultura, e os tratos culturais foram feitos conforme Nogueira et al. (2017). O bananal foi conduzido sem irrigação.

Durante a condução do bananal houve a presença das pragas broca gigante da bananeira (Castnia licus), abelha arapuá (Trigona spinipes), tripes da erupção dos frutos (Frankliniella spp.) e ocorrência das doenças do mal do panamá (Fusarium oxysporum f. sp. cubense) e sigatoka-negra (M. fijiensis). O controle fitossanitário da sigatoka-negra foi realizado com fungicida flutriafol (NOGUEIRA et al., 2017).

O delineamento experimental utilizado foi em blocos casualizados quatro tratamentos e cinco repetições. Os tratamentos consistiram de quatro épocas de colheitas, realizadas nos meses de fevereiro, março, abril e maio de 2014, sendo colhidos num total de 100 cachos aleatoriamente. Para cada época foram avaliados 25 cachos, os quais foram divididos em cinco repetições para avaliação das características físico-químicas e de coloração. A colheita foi realizada quando os frutos apresentaram o máximo crescimento. Os frutos, da segunda penca, foram armazenados na bancada do laboratório sob condições ambiente de temperatura e umidade relativa, onde permaneceram até atingir o grau de maturação $\mathrm{V}$, ou seja, frutos com coloração amarela e extremidades ainda verdes, que apresentam características ideais de colheita para o consumo in natura (HANSEN et al., 2012).

Avaliou-se o comprimento e o diâmetro do fruto, $0 \mathrm{pH}$ (potencial hidrogeniônico), o SST (sólidos solúveis totais), a ATT (acidez total titulável) e a relação SST/ATT (Ratio). A coloração da casca do fruto também foi analisada através do uso do colorímetro Minolta, modelo CR 300, o qual expressa à cor em 
três parâmetros ( $\mathrm{L}^{*}, \mathrm{C}^{*}$ e ângulo $\left.{ }^{\circ} \mathrm{Hue}\right)$, que juntos mostram no espaço à coloração do fruto (Figura 2). $O L^{*}$ representa a luminosidade ou brilho e varia de 0 (preto) a 100 (branco); o $\mathrm{C}^{*}$ define à cromaticidade ou pureza da cor, onde valores menores representam cores impuras (acinzentadas), e os maiores, às cores puras; e o ângulo oHue, que expressa a tonalidade ou cor verdadeira, que vai de $0^{\circ}$ a $360^{\circ}$, tendo-se 0 ângulo $0^{\circ}$ correspondente à cor vermelha, $90^{\circ}$ à cor amarela, $180^{\circ}$ ou $-90^{\circ}$ à cor verde, $270^{\circ}$ ou $-180^{\circ}$ à cor azul, e passa de vermelho a negro em $360^{\circ}$ (CASTRICINI et al., 2015; CASTRICINI et al., 2016). Realizaram-se duas leituras na região equatorial de cada fruto.

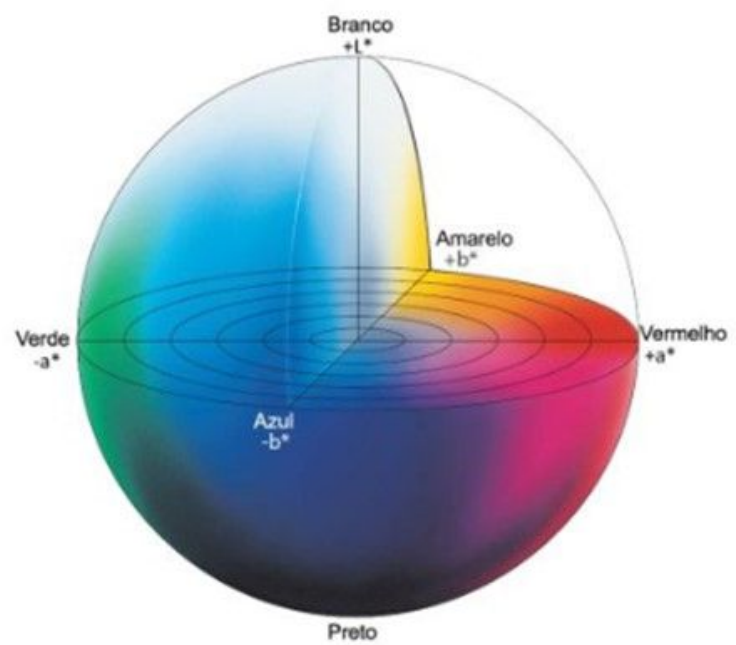

FIGURA 2. Diagrama de cores que representam os parâmetros $L^{*}$ (luminosidade), $\mathrm{C}^{*}$ (cromaticidade) e ângulo ${ }^{\circ}$ Hue.

Fonte: Minolta (2007)

Os dados obtidos foram submetidos à análise de variância (teste $F$ ) e as médias foram comparadas pelo teste de Tukey ao nível de $5 \%$ de probabilidade.

\section{RESULTADOS E DISCUSSÃO}

Não houve diferença estatística entre as colheitas realizadas entre fevereiro e maio de 2014, sendo semelhantes para todas as características físicas e químicas avaliadas. Os valores médios obtidos para cada variável foram: comprimento do fruto $=27,35 \mathrm{~cm}$; diâmetro do fruto $=50,63 \mathrm{~mm}$; $\mathrm{ATT}=0,54 ; \mathrm{SST}=17,48^{\circ}$ Brix; Ratio= 34,22; e pH= 4,86. Conforme Chitarra e Chitarra (2005), as condições edafoclimáticas podem influenciar nas características físico-químicas dos frutos, comportamento diferente foi observado neste estudo, provavelmente devido às condições ambientais que se mantiveram praticamente constante (Figura 1) durante o enchimento e colheita dos frutos, além das práticas agronômicas serem semelhantes para às quatro épocas.

O comprimento médio do fruto foi semelhante ao obtido por Faria et al. (2010), ao avaliarem as características vegetativas, de rendimento e o comportamento de cultivares de bananeiras tipo Terra, nas condições semiáridas de Guanambi-BA, em primeiro ciclo de produção sob manejo irrigado, onde observaram comprimento de $26,10 \mathrm{~cm}$ para a cv. D'angola, entretanto, encontraram diâmetro de $40,60 \mathrm{~mm}$, cerca de $24,70 \%$ inferior ao obtido neste trabalho. Com esta mesma cultivar, Prata et al. (2018) encontraram resultados superiores para o comprimento $(31,30 \mathrm{~cm})$ e similar para o diâmetro do fruto $(52 \mathrm{~mm})$ conduzido sob sistema irrigado 
e em diferentes densidades de plantio, em ambiente semiárido de Chapada do Apodi-CE.

Hansen et al. (2012), ao analisarem as características físicas e químicas de banana tipo Terra, cv. Maranhão, em três estádios de maturação, observaram comprimento do fruto de $22,94 \mathrm{~cm}$ e diâmetro $45,10 \mathrm{~mm}$ no estádio V. Estas diferenças no tamanho dos frutos são decorrentes de fatores diversos, como práticas agronômicas e região produtora (CHITARRA; CHITARRA, 2005; CASTRICINI et al., 2016; ARAÚJO; NASSUR, 2017).

O comprimento do fruto é um aspecto utilizado para fins de classificação e padronização, o que o constitui como importante atributo para o melhoramento de bananeiras, quando se trata da qualidade do fruto, já que o preço de venda às vezes depende do tamanho da banana (FARIA et al., 2010). Além disso, este carácter é considerado pelos consumidores no ato da compra e deve apresentar pouca variação entre as unidades, para que a escolha não seja afetada (CHITARRA; CHITARRA, 2005). Já o diâmetro pode ser utilizado como indicador de colheita na maioria das cultivares como a Prata e a Maçã, mas, não é totalmente válido para as cultivares do tipo Terra, que mesmo após maduras as quinas ou angulosidades da superfície dos frutos permanecem expostas (NOGUEIRA et al., 2017).

A ATT foi similar a observada em outros trabalhos com cultivares do subgrupo triploide $A A B$, com valores médios entre 0,51 e 0,55 (CERQUEIRA et al., 2002; HANSEN et al., 2012). Além disso, está dentro da faixa de 0,19 a 0,65 aferida por Cerqueira et al. (2002) ao avaliarem às características de pós-colheita de diversos genótipos de bananeira nas condições de Cruz das Almas-BA. Quanto ao teor de SST, o resultado foi inferior aos obtidos por estes autores, os quais observaram ${ }^{\circ}$ Brix médio entre 21,90 e 23,42 para cultivares triploides, porém, dentro da faixa de 16,82 e 23,42 reportada por Cerqueira et al. (2002) para diversos genótipos.

Os resultados de SST também foram inferiores aos verificados por Vilete et al. (2016), Araújo e Nassur (2017) e por Viana et al. (2017), entretanto, foi superior aos encontrados por Castricini et al. (2016) para as colheitas realizadas aos 90, 110 e 130 dias após a floração. Os SST são utilizados como uma medida indireta do teor de açúcar e aumentam com a maturação dos frutos, em decorrência de processos sintéticos ou degradação dos polissacarídeos (CHITARRA; CHITARRA 2005; SARMENTO et al., 2015; SANTOS et al., 2018). Segundo Hanson et al. (2012), frutos com maiores teores de SST são mais desejáveis, pois promovem melhor sabor para o consumo, seja in natura, fritos, cozidos ou industrializados.

O Ratio também foi inferior aos observados em outros trabalhos com cultivares triploides (CERQUEIRA et al., 2002; HANSEN et al., 2012; ARAÚJO; NASSUR, 2017; VIANA et al., 2017). No entanto, foi superior às cultivares BRS Preciosa e BRS Vitória avaliados por Viana et al. (2017) e próximos aos genótipos PV42-85, ST42-08 e YB42-21 analisados por Cerqueira et al. (2002).

$\mathrm{O}$ pH para bananas maduras varia entre 4,2 e 4,7, e de 5,0 a 5,6 para verdes (BLEINROTH, 1985). Porém, o resultado deste estudo foi levemente acima desta faixa, mas corrobora com Viana et al. (2015) que obtiveram $\mathrm{pH}$ de 4,81 para a cultivar BRS Caipira e 5,0 para cv. Grande Naine, e com Araújo e Nassur (2017) para a cv. Nanicão com valor médio de 4,90. Assim como as características físicas, as diferenças nos atributos químicos são decorrentes de diversos fatores, como o manejo fitotécnico, cultivares, condições de clima, dentre outros (CHITARRA; CHITARRA, 2005; CASTRICINI et al., 2016).

Quanto à coloração da casca dos frutos, também não foram observadas influência significativa das épocas de colheitas. Em média, a luminosidade $\left(L^{*}\right)$ foi de 
65,83; a cromaticidade $\left(\mathrm{C}^{*}\right)$ de 50,27; e o ângulo o Hue de 85,27. A falta de significância pode ser devido ao armazenamento dos frutos nas mesmas condições de ambiente para o amadurecimento, práticas agronômicas iguais para todas as épocas de colheita, e condições climáticas praticamente constante durante 0 crescimento dos frutos (Figura 1).

A luminosidade varia entre 0 (preto/opaco) e 100 (branco), e quanto menor for o valor, indica que a cor da casca é opaca ou sem brilho, e quanto maior representa máximo brilho. Dessa forma, todas as épocas de colheitas proporcionaram frutos com luminosidade semelhantes, com valores situados de médio a alto brilho. Os resultados deste parâmetro foram menores que os obtidos por Castricini et al. (2015), que aferiram valores de 74,43 a 77,12 com diferentes idades de colheita e por Castricini et al. (2016), que observaram médias de 70,43 a 72,96 com diferentes cultivares na época de colheita comercial e no estágio de maturação VI, indicando que a casca do fruto com tonalidade amarela foi mais brilhosa que a deste trabalho. Já para a cromaticidade, o valor médio ficou entre os 35,40 e 54,59 encontrados por estes autores, e acima dos obtidos por Santos et al. (2018).

Os valores de tonalidade de cor da casca (ângulo oHue) de todas as colheitas situaram-se dentro faixa angular de coloração amarela, porém, com menor intensidade que as observadas em outros estudos (CASTRICINI et al., 2015; CASTRICINI et al., 2016), diferenças em virtude do estágio de maturação.

$\mathrm{O}$ amarelecimento ou mudança de cor da casca da banana tem como evento principal a degradação da clorofila (cor verde), sendo a síntese de outros pigmentos realizada em níveis relativamente baixos. Durante este processo, fica visível a préexistência dos pigmentos carotenoides (cor amarelo a laranja) (SARMENTO et al., 2015). Segundo Castricini et al. (2015), durante o amadurecimento dos frutos ocorre a degradação das clorofilas, como a síntese de carotenoides, que são processos articulado pelo gás etileno, e segundo eles o ângulo Hue permite observar a mudança nos pigmentos do verde ao amarelo.

\section{CONCLUSÕES}

As épocas de colheitas não influenciam nas características pós-colheita de bananas da cv. D’angola produzidas nas condições edafoclimáticas do Acre.

As bananas produzidas entre fevereiro e maio possuem qualidade póscolheita dentro do padrão aceito para comercialização.

\section{AGRADECIMENTOS}

À Embrapa Acre pelo apoio na execução do experimento, à Coordenação de Aperfeiçoamento de Pessoal de Nível Superior (CAPES) pelo incentivo à pesquisa científica e à Universidade Federal do Acre pela oferta da Pós-Graduação em Produção Vegetal.

\section{REFERÊNCIAS}

AGRITEMPO. Sistema de monitoramento agrometeorológico. Disponível em $<$ https://www.agritempo.gov.br/agritempo/index.jsp>. Acesso em: 05 dez. 2018.

ARAÚJO, J. F.; NASSUR, R. de C. M. Qualidade de frutos de variedades de bananeiras sob cultivo orgânico e irrigado no semiárido. Revista Agropecuária Científica no Semiárido, v. 13, n. 2, p. 138-145, 2017. DOI: http://dx.doi.org/10.30969/acsa.v13i2.825 
BLEINROTH, E.W. Matéria prima. In: MEDINA, J.C.; BLEINROTH, E.W.; MARTIN, Z.J.; MORETTI, V.A. Banana: cultura, matéria-prima, processamento e aspectos econômicos. 2 ed. rev. e ampl. Campinas: Instituto de Tecnologia de Alimentos, 1985, p. 133-196, 1985.

CASTRICINI, A.; DIAS, M. S. C.; RODRIGUES, M. G. V. Pós-colheita de banana 'BRS Tropical' em função do manejo fitotécnico. Caderno de Ciências Agrárias, v. 8, n. 3, p. 52-62, $2016 . \quad$ Disponível em: <https://periodicos.ufmg.br/index.php/ccaufmg/article/ view/2928>. Acesso em: 10 fev. 2019.

CASTRICINI, A.; SANTOS, L. O.; DELIZA, R.; COELHO, E. F.; RODRIGUES, M. G. $\mathrm{V}$. Caracterização pós-colheita e sensorial de genótipos de bananeiras tipo prata. Revista Brasileira de Fruticultura, Jaboticabal, v. 37, n. 1, p. 027-037, 2015. DOI: http://dx.doi.org/10.1590/0100-2945-058/14.

CERQUEIRA, R.C.; SILVA, S.O.; MEDINA, V.M. Características pós-colheita de frutos de genótipos de bananeira (Musa spp.). Revista Brasileira de Fruticultura, v. 24 , n. 3, p. 654-657, 2002. DOI: http://dx.doi.org/10.1590/S010029452002000300020

CHITARRA, M. I.; CHITARRA, A. B. Pós-Colheita de frutos e hortaliças: Fisilologia e Manuseio. 2 ed. rev. e ampl. Lavras: UFLA, 2005, 785 p.

FARIA, H. C.; DONATO, S. L. R.; PEREIRA, M. C. T.; SILVA, S. O. Avaliação fitotécnica de bananeira tipo terra sob irrigação em condições semi-áridas. Ciência e Agrotecnologia, v. 34, n. 4, p. 830-836, 2010. DOI: http://dx.doi.org/10.1590/S141370542010000400006.

HANSEN, O. A. de S.; FONSECA, A. A. O.; HANSEN, D. de S. Caracterização física e química da banana 'terra maranhão' em três estádios de maturação. Magistra, Cruz das Almas, v. 24, n. 1, p. 27-33, 2012.

IBGE. Produção agrícola municipal. [2019]. Disponível em: <www.sidra.ibge. gov.br>. Acesso em: 02 fev. 2019.

MINOLTA, K. Precise color communication: color control from perception to Instrumentation. Konica Minolta Sensing, Incorporated, 2007, 61 p. Disponível em: <https://www.konicaminolta.com/instruments/knowledge/color/pdf/color_communicati on.pdf>. Acesso em: 13 fev. 2019.

MOTA, J. D.; QUEIROZ, A. J. de M.; FIGUEIRÊDO, R. M. F. de; SOUSA, K. dos S. M. de. Índice de cor e sua correlação com parâmetros físico-químicos de goiaba, manga e mamão. Comunicata Scientiae, v. 6, n. 1, p. 74-82, 2015.

NOGUEIRA, S. R.; ANDRADE NETO, R. de C.; NASCIMENTO, G. C. do; GONZAGA, D. S. de O. M. (Ed.). Sistema de produção de banana para o estado do Acre. Rio Branco, AC: Embrapa Acre, 2017. (Sistema de produção, 7). Disponível em: <https://www.spo.cnptia.embrapa.br>. Acesso em: 09 fev. 2019.PRATA, R. C.; SILVA, J.; LIMA, Y. B.; ANCHIETA, O. F. A.; DANTAS, R. P. et 
al. Densidade de plantio no crescimento e produção de plátano cv. D’Angola na Chapada do Apodi. Revista Agropecuária Técnica, v. 39, n. 1, p. 15-23, 2018. DOI: 10.25066/agrotec.v39i1.35830

SANTOS, T. C.; AGUIAR, F. S.; RODRIGUES, M. L. M.; MIZOBUTSI, G. P.; PINHEIRO, J. M. da S. Quality of bananas harvested at different development stages and subjected to cold storage. Pesquisa Agropecuária Tropical, Goiânia, v. 48, n. 2, p. 90-97, 2018. DOI: http://dx.doi.org/10.1590/1983-40632018v4851297

SARMENTO, D. H. A.; SOUZA, P. A. de; SARMENTO, J. D. A.; FREITAS, R. V. da S.; SALGADO FILHO, M. Armazenamento de banana 'Prata Catarina' sob temperatura ambiente recobertas com fécula de mandioca e PVC. Revista Caatinga, v. 28, n. 2, p. 235-241, 2015. Disponível em: <https://periodicos.ufersa.edu.br/ index.php/caatinga/article/view/2980/pdf_266>. Acesso em: 12 fev. 2019.

TAIZ, L.; ZEIGER, E. Fisiologia e desenvolvimento vegetal. 6. ed. Porto Alegre: Artmed, 2017. $858 \mathrm{p}$.

VIANA, E. de S.; REIS, R. C.; SENA, L. de O.; SANTOS JÚNIOR, M. B. dos; SILVA, P. N. R. da. Produção de bananas-passa com frutos de variedades melhoradas e avaliação da qualidade físico-química e sensorial. Boletim Centro de Pesquisa de Processamento de Alimentos, v. 35, n. 1, p. 1-10, 2017. Disponível em: <https://revistas.ufpr.br/alimentos/article/view/55944/33720>. Acesso em: 09 fev. 2019.

VILETE, J. V.; POLETTO, B. de O.; VIEIRA, R. Extração de lipídeos da banana-daterra madura e tratamento de dados utilizando ferramentas quimiométricas. Revista Científica da Faculdade de Educação e Meio Ambiente, v. 2, n. 7, p. 90-110, 2016. Disponível em: <http://repositorio.faema.edu.br:8000/bitstream/123456789/1806/1/ VILETE\%20et\%20al..pdf>. Acesso em: 12 fev. 2019. 